\title{
Discriminating time intervals presented in sequences marked by visual signals
}

\author{
SIMON GRONDIN \\ Université Laval, Quebec, Quebec, Canada
}

\begin{abstract}
This article presents the results of three experiments on the discrimination of time intervals presented in sequences marked by brief visual signals. In Experiment 1A (continuous condition), the participants had to indicate whether, in a series of 2-4 intervals marked by $3-5$ visual signals, the last interval was shorter or longer than the previous one(s). In Experiment 1B (discontinuous condition), the participants indicated whether, in a presentation of two series of 1-3 intervals, with each series being marked by 2-4 signals, the intervals of the second sequence were shorter or longer than those of the first. Whenever one, two, or three standard intervals were presented, the difference threshold was as high at $150 \mathrm{msec}$ as it was at $300 \mathrm{msec}$ with the continuous method but increased monotonically from 150 to 900 msec with the discontinuous method. With both methods, the increase was well described by Weber's law - the Weber fraction was roughly constant-between 600 and $900 \mathrm{msec}$ (Experiment 2), whereas between 900 and 1,200 msec (Experiment 3), the Weber fraction increased.
\end{abstract}

According to Weber's law, the ratio of the difference threshold to the magnitude is a constant-that is, the Weber fraction (WF), which remains the same over a given range of sensory magnitudes. This law is often reported to apply to human time perception, more specifically to the field of single-interval discrimination (Allan \& Kristofferson, 1974; Grondin, 1993; Ivry \& Hazeltine, 1995; Killeen \& Weiss, 1987; Nakajima, 1987). Also, in the animal timing literature, one of the most influential theories is that of scalar timing, which implies Weber's law (Allan, 1998).

Many recent empirical reports on duration discrimination are based on methods in which interval sequences, which are marked by series of auditory signals, are presented (McAuley \& Kidd, 1998; ten Hoopen et al., 1994). Although some of these reports have supported a Weber's law model (Halpern \& Darwin, 1982; Hirsh, Monahan, Grant, \& Singh, 1990; Monahan \& Hirsh, 1990; see

Experiment 1 was presented at the 39th Annual Meeting of the Psychonomic Society, held in Dallas in 1998. Experiment 2 was presented at the 9th Annual Meeting of the Canadian Society for Brain, Behaviour, and Cognitive Science, held in Edmonton in 1999. Experiment 3 was presented at 27th International Congress of Psychology, held in Stockholm in 2000 . This research was supported by a grant from the Natural Sciences and Engineering Research Council of Canada. I thank Christian Blanchette, Marzena Jarek, Julie Poulin, and Christian Watier for their dedication as participants in Experiments 1A and 1B. I extend special thanks to Karine Gauthier, Isabelle Guay, and Mélanie Lapointe for their help in data collection and to Stan Koren, from Laurentian University, who wrote the computer programs. For their valuable comments during the course of this project or on an earlier draft of this article, I am grateful to James Everett and Gert ten Hoopen and to one anonymous reviewer, who proposed Experiment 3. Correspondence concerning this paper should be addressed to S. Grondin, École de Psychologie, Université Laval, Quebec, PQ G1K 7P4, Canada (e-mail: simon.grondin@psy.ulaval.ca).
Friberg \& Sundberg, 1995, for a review of the research on auditory isochronous sequences), other reports have called the Weber's law model into question. Systematic deviations from Weber's law can be partly associated with two methods for presenting intervals to be discriminated.

In one method, participants are presented with temporal patterns made of a series of brief auditory sounds in which, for example, the second sound of a series of three marks the end of the first interval and the beginning of the next one. In this continuous condition, participants are asked to judge the duration of the last interval relative to the preceding one(s). Surprisingly, in such conditions, the difference threshold (and not the WF) was found to remain constant for intervals lasting 50, 100, and $200 \mathrm{msec}$ (ten Hoopen et al., 1995). Schulze (1989), who also used a continuous method, reported a constant difference threshold value for intervals lasting 50, 100, 200 , and $400 \mathrm{msec}$. This result applied whether two, three, four (ten Hoopen et al., 1995), or even five or six (Schulze, 1989) successive intervals were presented. Along the same line, Friberg and Sundberg (1995) also used a continuous method but, instead of having the last interval different from the previous ones, a nonstandard interval was inserted into the series. These authors reported that the difference threshold had a constant value for intervals lasting 100-240 msec. On the other hand, this constant difference threshold effect may depend simply on the range of the duration investigated. Halpern and Darwin (1982) reported, with a continuous method, a monotonic increase of the difference threshold for durations lasting $400-1,450 \mathrm{msec}$.

A second case of a violation of Weber's law has been reported when intervals presented in a sequence of two or more sounds marking at least one interval are to be discriminated from intervals presented in a second sequence 

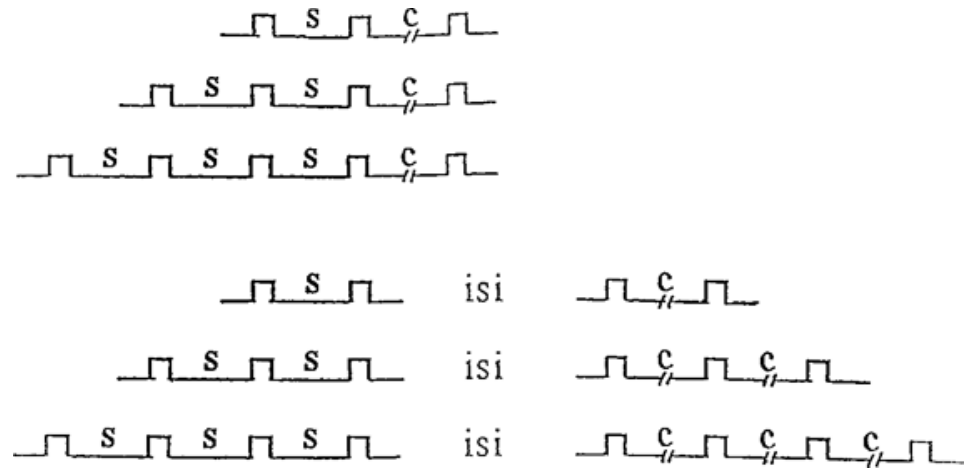

Figure 1. Presentation of one, two, or three standard intervals in Experiments $1 \mathrm{~A}$ (upper panel) and $1 \mathrm{~B}$ (lower panel). s, standard interval; c, comparison interval; isi, interstimulus interval.

(discontinuouscondition). Drake and Botte (1993) reported that, for intervals lasting 100-1,500 msec, sensitivity was at its maximum (lower WFs) for intervals of 300-800 msec. This finding was consistent with Fraisse (1967), who reported that temporal sensitivity was at its best when the intervals between a sequence of tones were about $600 \mathrm{msec}$. Similarly, one may note in Friberg and Sundberg (1995) that, for intervals lasting 0.1-1 sec, the WF was at its minimum at $500 \mathrm{msec}(2.1 \%$, in comparison with $2.7 \%$ at 380 and $800 \mathrm{msec}$; no 600 -msec condition was investigated).

To sum up, there are some reports, such as the one of Halpern and Darwin (1982), supporting Weber's law for the discrimination of intervals marked by the sequences of auditory signals. However, depending on the method used to present the sequences of intervals, this law is incorrect. For intervals lasting up to $400 \mathrm{msec}$ and presented with a continuous method, it is the difference threshold, not the WF, that remains constant with time (Schulze, 1989; ten Hoppen et al., 1995). On the other hand, with a discontinuous method, there is a point, as the standard duration becomes longer, at which nonmonotonicity of the WF occurs: This fraction increases with intervals longer than $800 \mathrm{msec}$ (Drake \& Botte, 1993). These method-related variations that induce oddities in the Weber function may reflect a feature of the auditory system for the processing of time. In order to test whether such patterns of results reflect a more general property of temporal processing, rather than a property of auditory processing, the continuous and discontinuous methods were employed in the present study for the discrimination of intervals marked by visual signals.

In addition to the comparison of the continuous and the discontinuous methods described above, the effect of the number of intervals presented was tested. According to Drake and Botte (1993), the use of multiple presentations of intervals, instead of single presentations, should allow development of a more precise memory trace of mean interval duration, which would result in better discrimination.

Finally, the methods employed in the present study also compel giving special attention to the perceived du- ration of the intervals to be judged. When sequences of intervals are presented, it is well known that the perceived duration of these intervals will not be independent. This distortion of time is generally referred to as the time order error (TOE; Allan \& Gibbon, 1994; Hellström, 1985; Jamieson \& Petrusic, 1975a, 1975b). Depending on several factors, such as the range of durations under investigation and the interstimulus interval (ISI), duration may be severely underestimated or overestimated. Recently, Nakajima, ten Hoopen, and collaborators have offered a series of studies showing that the presentation of sequences of successive intervals produces an impressive TOE that they called a time shrinking illusion (Nakajima, ten Hoopen, Hilkhuysen, \& Sasaki, 1992; Nakajima, ten Hoopen, \& van der Wilk, 1991; ten Hoopen et al., 1993). For instance, in the continuous method described earlier, the last interval of a series should last about $78 \mathrm{msec}$ in order to be perceived to be as long as the preceding 50-msec standard intervals. Another duration illusion was reported recently, this time involving 600-msec intervals presented visually (Rose \& Summers, 1995). In this experiment, instead of a sequence of brief sensory signals being used to mark empty intervals, a series of light flashes was used to mark filled visual intervals. The first of a series of four intervals had to be considerably shortened to appear to have the same duration as the following intervals. Indeed, the first interval was overestimated by as much as $50 \%$.

\section{EXPERIMENT 1A Continuous Method}

\section{Method}

Participants. Four 20- to 26-year-old volunteer students at Université Laval, 2 males and 2 females, participated in this experiment. They were paid $\$ 6$ per session for their participation.

Apparatus and Stimuli. Each participant was seated in a chair in a dimly lit room. The ambient light was kept constant throughout the experiment. The participants were asked to respond either short or long by pressing, respectively, the left or the right button of a small response box. The experiment was controlled by a Zenith microcomputer. 
Participant 1
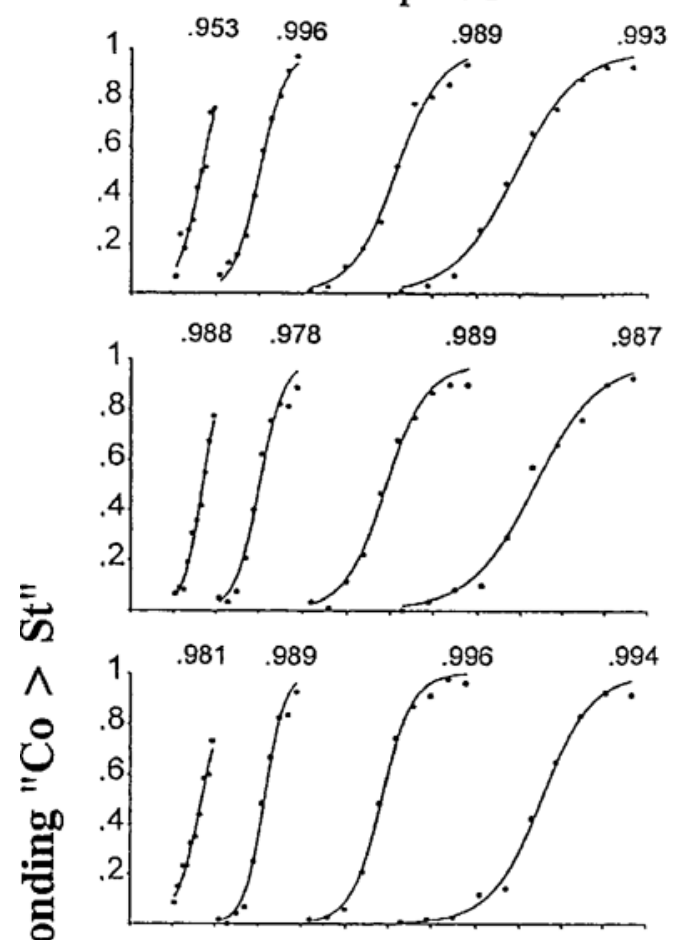

Participant 3

突
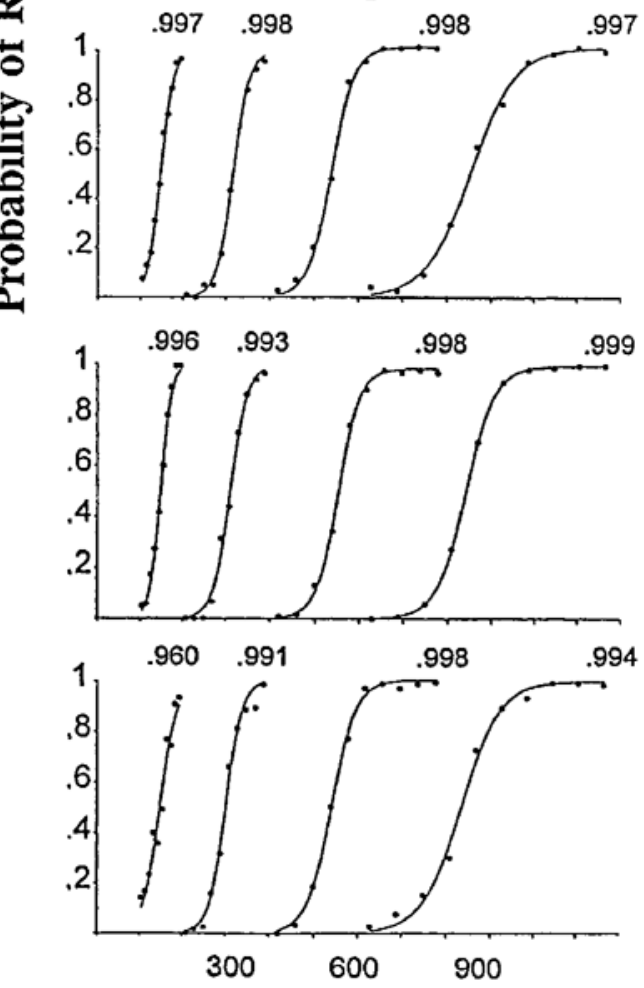

Participant 2

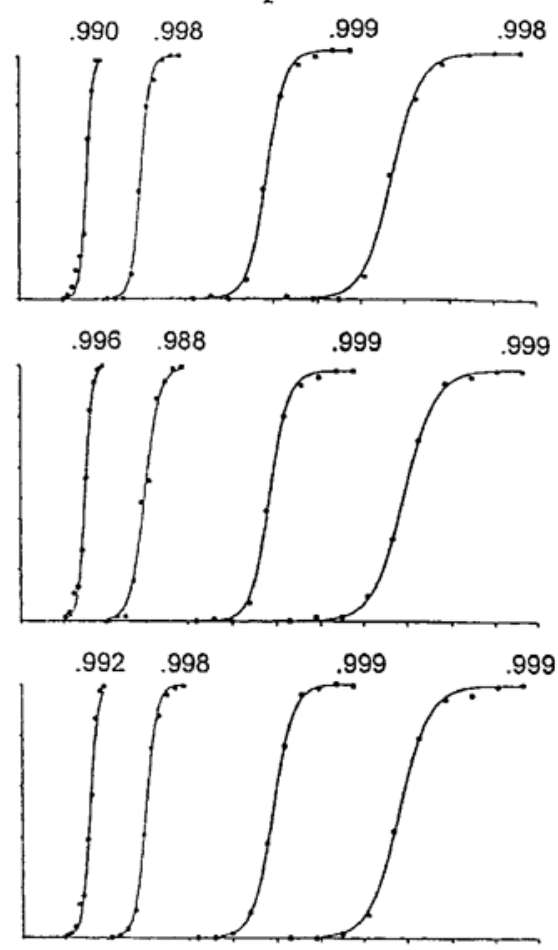

Participant 4
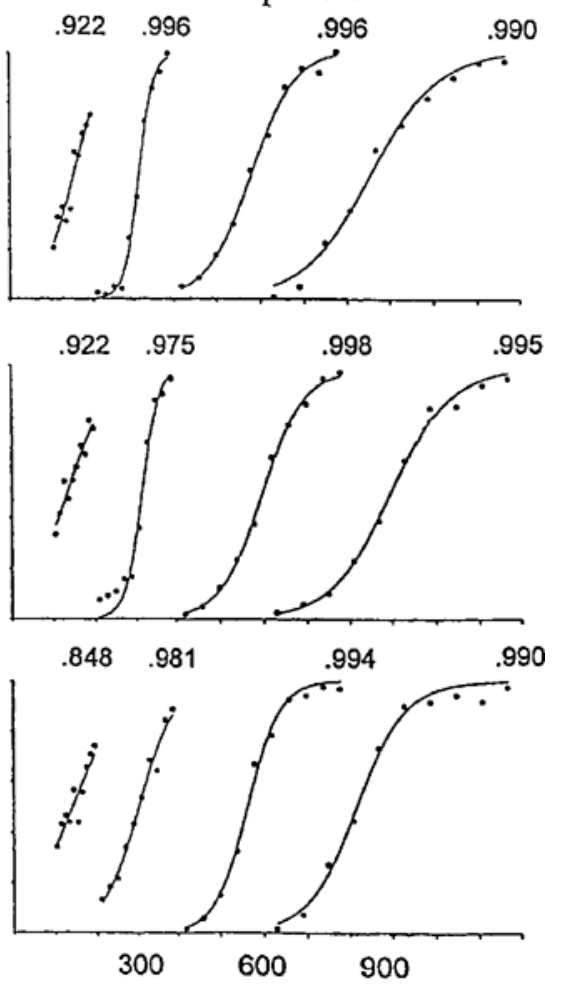

Comparison Interval (msec)

Figure 2. Individual psychometric functions in each experimental condition of Experiment 1A. For each participant, the one-, two-, and three-standards presentation conditions correspond to the upper, middle, and lower panels, respectively. Co, comparison interval; St, standard interval. Numbers above each function are $R^{2}$. 


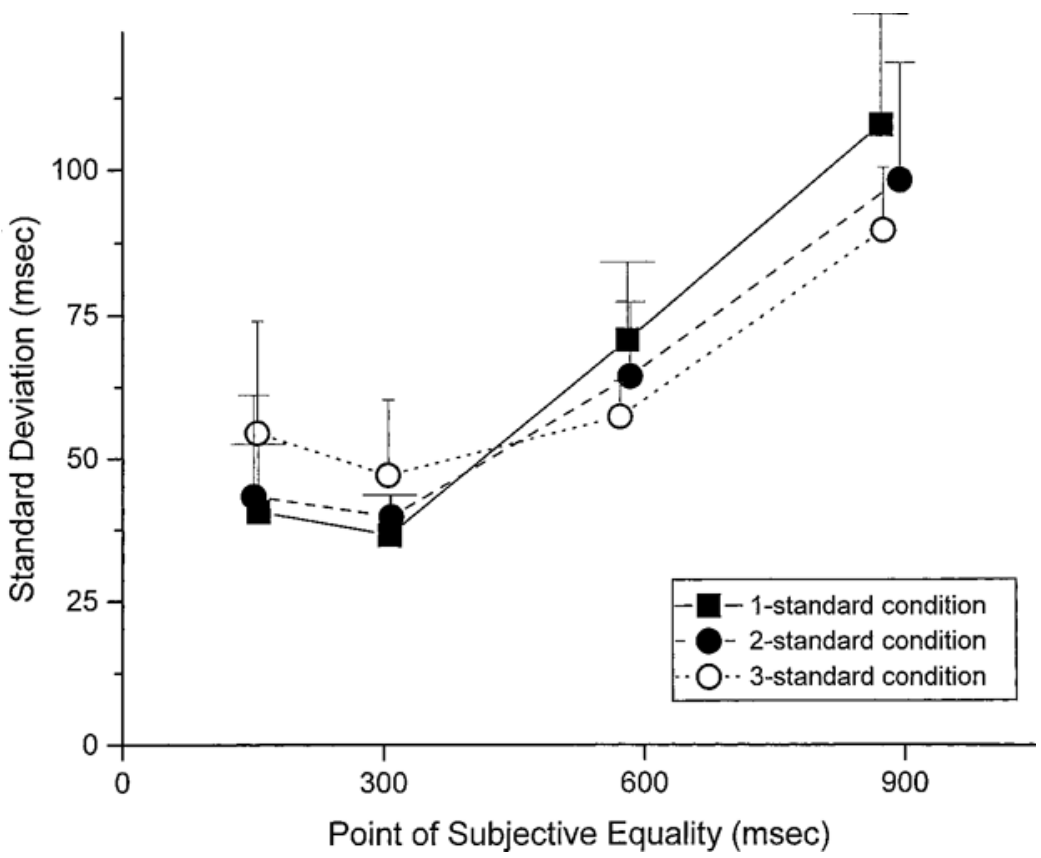

Figure 3. Mean standard deviations in each experimental condition of Experiment $1 \mathrm{~A}$, as a function of the point of subjective equality.

Each interval was marked by successive 10 -msec visual stimulations. The visual signal consisted of a circular red light-emitting diode (LED; Radio Shack No. 276-088). The LED was located about $1 \mathrm{~m}$ in front of the participant, subtending a visual angle of $0.57^{\circ}$.

Procedure. Each trial consisted of the presentation of three, four, or five visual signals marking two, three, or four intervals, respectively. This procedure follows ten Hoopen et al. (1995; see their Experiment 1). The participants were asked to indicate, by pressing the appropriate button, whether the last interval (comparison) of the sequence was shorter or longer than the previous one(s), which was the standard (see Figure 1, upper panel). There were 4 standardinterval conditions: $150,300,600$, and $900 \mathrm{msec} .{ }^{1}$ In other words, there were 12 experimental conditions under investigation: 4 base durations $\times 3$ numbers of standards.

For each standard interval, there were 10 comparison intervals. At $150 \mathrm{msec}$, the comparison intervals lasted from 105 to $195 \mathrm{msec}$, in steps of $10 \mathrm{msec}$. With the $300-\mathrm{msec}$ standard, the value of the comparison intervals was doubled $(210-390 \mathrm{msec})$. These values were doubled (420-780 msec) and tripled (630-1,170 msec) for the 600- and 900-msec standard conditions, respectively. It should be noted that these values were based on previous observations and were arranged so that the task would not be too difficult, at the expense of having some data points representing perfect scores.

After the presentation of the intervals, the participants had $10 \mathrm{sec}$ to respond, and $2 \mathrm{sec}$ after their responses, the signals marking the intervals for the next trial were presented. As in ten Hoopen et al. (1995), there was no feedback. Each session was divided into four blocks of 100 trials. Within each block, there were 10 repetitions of each of the 10 comparison-interval conditions. Between the blocks, there was a 30 -sec pause.

In any given session, only 1 of the 12 experimental conditions was investigated. There were 3 consecutive sessions for each experimental condition. Thus, there were 120 judgments for each comparison interval: 3 sessions $\times 4$ blocks $\times 10$ repetitions. There were 36 sessions: $3 \times 12$ experimental conditions. The order of presentation of the 4 base duration conditions was varied according to a Latin square. The order of presentation of the 3 sequence conditions was only partially balanced.

The participants had free access to the laboratory. They were informed as to how to start the experiment. Thus, they were free to participate at any time but were instructed to make sure they were sufficiently alert to pay attention to the task for a complete session.

Data analysis. For each participant and for each of the 12 experimental conditions, a 10-point psychometric function was traced, plotting the 10 comparison intervals on the $x$-axis and the probability of responding long on the $y$-axis.

Traditionally, the model used to fit the data points on a psychometric function has the cumulative normal distribution (CND). Strictly speaking, use of the CND for fitting data points on a psychometric function might not make sense. If Weber's law applies to time, a model such as the CND leads to perhaps slight, but systematic, fitting error. Weber's law predicts a positively skewed psychometric function, whereas the CND is a symmetrical model. Killeen,

Table 1

Slope, Intercept, and Explained Variance $\left(R^{2}\right)$ Derived from Equation 2 for Mean Results in Each Standard-Presentation Condition of Experiment 1A (Continuous Condition) and of Experiment 1B (Discontinuous Condition)

\begin{tabular}{cccc}
$\begin{array}{l}\text { Number of } \\
\text { Standards }\end{array}$ & Slope & Intercept & $R^{2}$ \\
\hline \multicolumn{3}{c}{ Continuous } \\
1 & .01446 & 551.56 & .985 \\
2 & .01069 & 993.39 & .980 \\
3 & .00758 & $1,862.03$ & .895 \\
& \multicolumn{3}{c}{ Discontinuous } \\
1 & .02650 & 56.07 & .999 \\
2 & .01907 & 107.72 & .999 \\
3 & .01378 & 632.34 & .991 \\
\hline
\end{tabular}




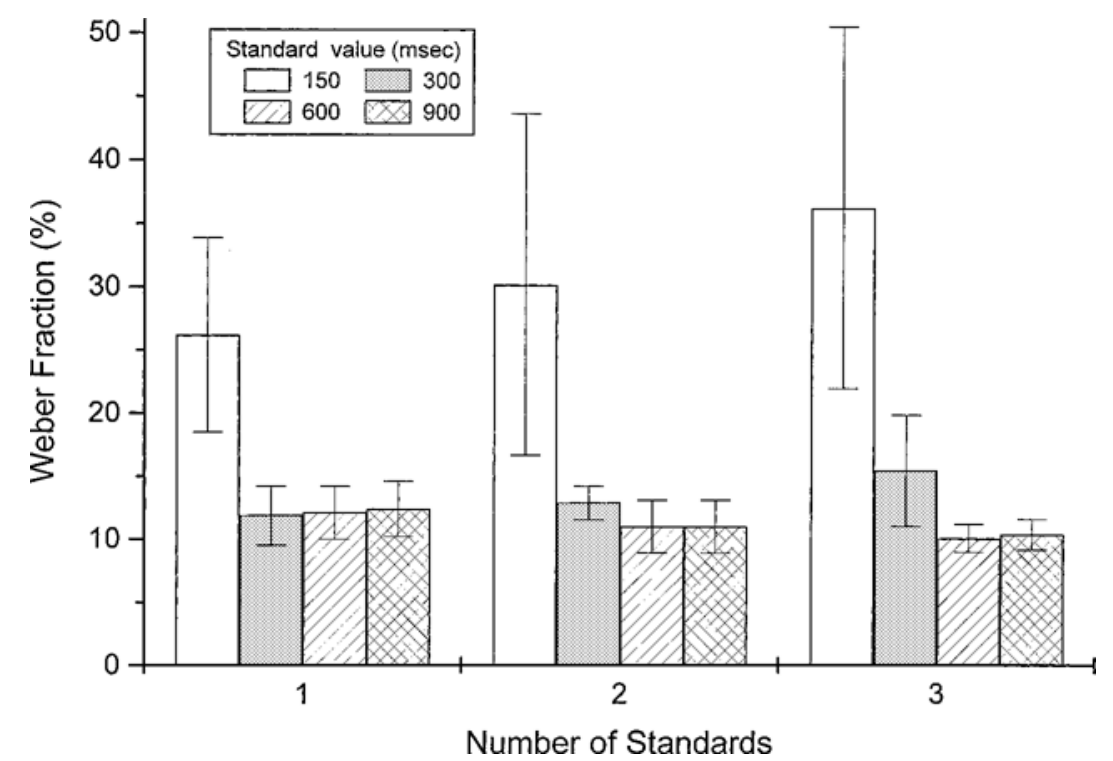

Figure 4. Mean Weber fractions (standard deviation/point of subjective equality) in each experimental condition of Experiment $1 \mathrm{~A}$.

Fetterman, and Bizo (1997) proposed to use what they called a pseudo-logistic function:

$$
p=\left[1+\exp \left(\mu-t / 0.55 \sigma_{t}\right)\right]^{-1},
$$

where $p$ is the probability of responding, for instance, that the comparison interval is longer than the standard and $t$ is the value of the comparison intervals. Two indices of performance were extracted from each psychometric function, one for sensitivity and one for the perceived duration. Sensitivity was measured with the estimate of one standard deviation $(S D ; \sigma$ in Equation 1$)$ on the psychometric function, and perceived duration was measured on the basis of the point of subjective equality (PSE; $\mu$ in Equation 1), which is the value on the $x$-axis corresponding to the $50 \%$ value on the $y$-axis. In order to address the question of the nonmonotonicity of the WF, this fraction was calculated by the ratio of the difference threshold, here measured as one $S D$, to the PSE (Ivry \& Hazeltine, 1995). Moreover, for providing a direct comparison of perceived duration across standard intervals, the constant error (CE) was also calculated: $\mathrm{CE}=\mathrm{PSE}-$ standard.

For analyzing the Weber function, we used the model proposed by Getty (1975) and by Ivry and Hazeltine (1995) for duration discrimination:

$$
\sigma^{2}=K^{2} t^{2}+C,
$$

where $\sigma^{2}$ is the square value of $\sigma$, defined above, associated with an interval, $t$. The square root of the slope of Equation 2 is the approximation of the WF for the experimental condition under investigation, and the intercept, $C$, is an estimate of the nontemporal error in the discrimination process - such as the beginning and end of the timekeeping activity when sensory signals occur.

\section{Results}

Each individual psychometric function is reported in Figure 2. For Participant 1, all the $R^{2}$ values were over .98 , except in the one-standard condition at $150 \mathrm{msec}\left(R^{2}=\right.$ $.953)$. For Participants 2 and 3 , all the $R^{2}$ values were higher than .987 , except in the three-standards condition at $150 \mathrm{msec}$ (Participant $\left.3, R^{2}=.96\right)$. All the fits were excellent for Participant $4,\left(R^{2}>.97\right)$, except at $150 \mathrm{msec}$.

Individual difference thresholds, also sometimes referred to below as standard deviations, were estimated in each experimental condition. Figure 3 shows, for each number-of-standards condition, the mean difference threshold as a function of the mean PSE. In all three conditions, difference thresholds were slightly higher at 150 msec than at $300 \mathrm{msec}$, but higher at $600 \mathrm{msec}$ than at $300 \mathrm{msec}$. Interestingly, although the highest thresholds were observed with the three-standards condition at both 150 and $300 \mathrm{msec}$, the lowest ones at 600 and $900 \mathrm{msec}$ were obtained with this three-standards condition. For all four standard durations, the two-standards condition provided intermediate thresholds.

The proportion of variance accounted for by Equation 2, a generalized form of Weber's law, is .985 and .980 in the one- and two-standards conditions, respectively. However, in the three-standards condition, this value falls to .895. It is in the one-standard condition that the WF is at its highest (.120) and $C$ at its lowest (552). The reversed situation, lowest WF (.081) and highest $C$ (1862), is observed in the three-standards condition. All values of the slope, intercept, and $R^{2}$ resulting from Equation 2 are reported in Table 1.

Weber fractions. Mean WFs in each of the 12 experimental conditions are illustrated in Figure 4. In general, the WF remained about the same, for all numbers of standards, from 300 to $900 \mathrm{msec}$. At $150 \mathrm{msec}$, we generally observed an increase of the WF, especially in the three-standards condition.

The difference between the means was tested with a randomized block factorial analysis of variance (ANOVA; 


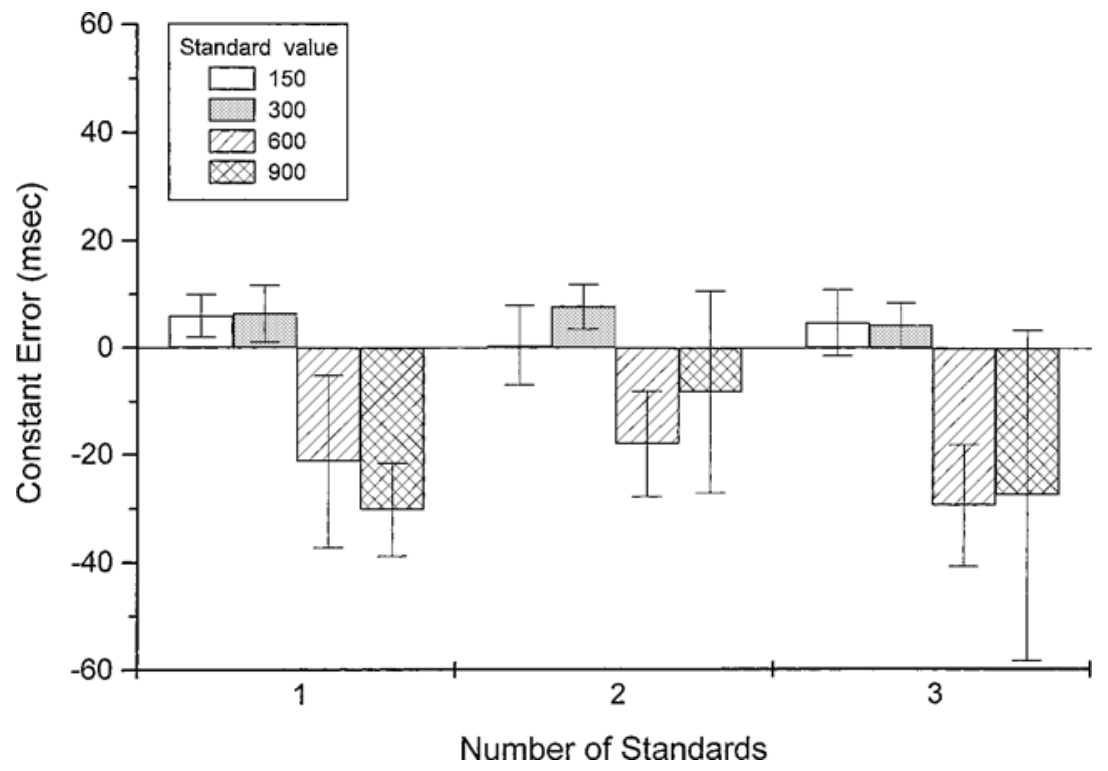

Figure 5. Mean constant errors in each experimental condition of Experiment $1 \mathrm{~A}$.

3 standards $\times 4$ durations). There was a significant effect only of duration $[F(3,33)=10.45, p<.01]$.

Constant error. The mean CEs in each experimental condition are reported in Figure 5. Note that positive values indicate a tendency to perceive the last interval as shorter than the standard. The CEs were small and positive at 150 and $300 \mathrm{msec}$, but large and negative at 600 and $900 \mathrm{msec}$. The difference between the means was tested with a randomized block factorial (ANOVA; 3 standards $\times 4$ durations; Kirk, 1982). There was a significant effect only of duration $[F(3,33)=6.60, p<.01]$.

\section{EXPERIMENT 1B}

As compared with Experiment 1A, there were two main changes in the present procedure: there was a discontinuity - that is, an ISI $(1.5 \mathrm{sec})$ between the presentations of the standard(s) and the comparison interval(s) and the latter was(were) presented as many times as the standard. This procedure is close to the one used by Drake and Botte (1993).

\section{Method}

Participants. The same 4 volunteer students as those in Experiment 1A participated in Experiment 1B. They completed all the conditions of Experiment 1A before participating in Experiment 1B. They were paid $\$ 6$ per session for their participation.

Apparatus and Stimuli. The material was the same as that in Experiment 1A.

Procedure. Each trial consisted of two, three, or four visual signals marking one, two, or three identical standard intervals, respectively. After $1.5 \mathrm{sec}$, another sequence of two, three, or four visual signals was presented to mark one, two, or three identical comparison intervals. The participants were asked to indicate, by pressing the appropriate button, whether the interval(s) of the last sequence, which was (were) the comparison interval(s), was (were) shorter or longer than the previous one(s), which was (were) the standard interval(s) (see Figure 1, lower panel). As in Experiment 1A, there were 4 standard-in terval conditions: $150,300,600$, and $900 \mathrm{msec}$. In other words, there were once again 12 experimental conditions under investigation: 4 durations $\times 3$ standards.

The rest of the procedure was identical to that in Experiment 1A.

\section{Results}

As in Experiment 1A, for each participant and for each of the 12 experimental conditions, a 10-point psychometric function was traced, using the same method. The functions are reported in Figure 6.

As in Experiment $1 \mathrm{~A}$, the $R^{2}$ values were generally very high. Except for Participant 4 at $150 \mathrm{msec}$ in the two-intervals condition $\left(R^{2}=.942\right)$, all the fits were excellent for Participants 1 and $4\left(R^{2}>.965\right)$ and for Participants 2 and $3\left(R^{2}>.993\right) .^{2}$

Figure 7 shows, for each number of standards, the mean difference threshold as a function of the mean PSE. In contrast to Experiment 1A, the relationship between difference threshold and interval duration was, for each number-of-standards condition, an increasing monotonic function. These relationships were analyzed in the light of Equation 2. The analysis indicated that the $R^{2}$ values were $.999, .999$, and .991 in the one-, two-, and three-standards conditions, respectively. As in Experiment $1 \mathrm{~A}$, it was in the one-standard condition that the WF was at its highest (.163) and $C$ at its minimum (56), and WF was at its lowest (.117), and $C$ at its highest (632) in the three-standards condition. All values of the slope, intercept, and $R^{2}$ resulting from using Equation 2 are reported in Table 1.

Weber fractions. Mean WFs in each of 12 experimental conditions are illustrated in Figure 8. In general, the increased WFs observed at $150 \mathrm{msec}$ were not as 
Participant 1

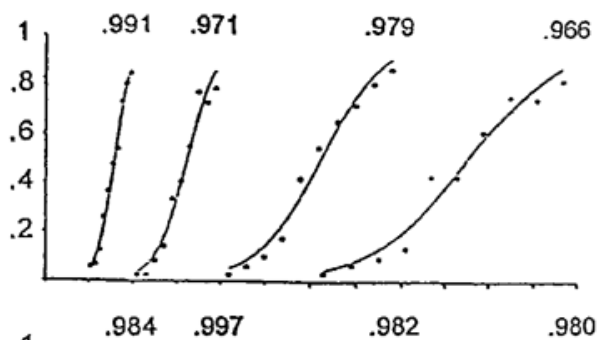

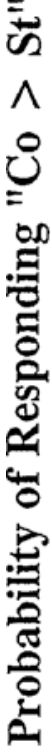
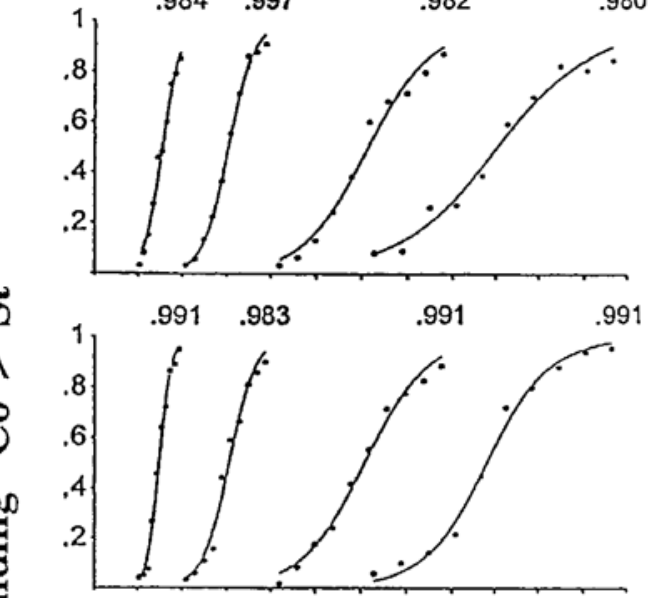

Participant 3
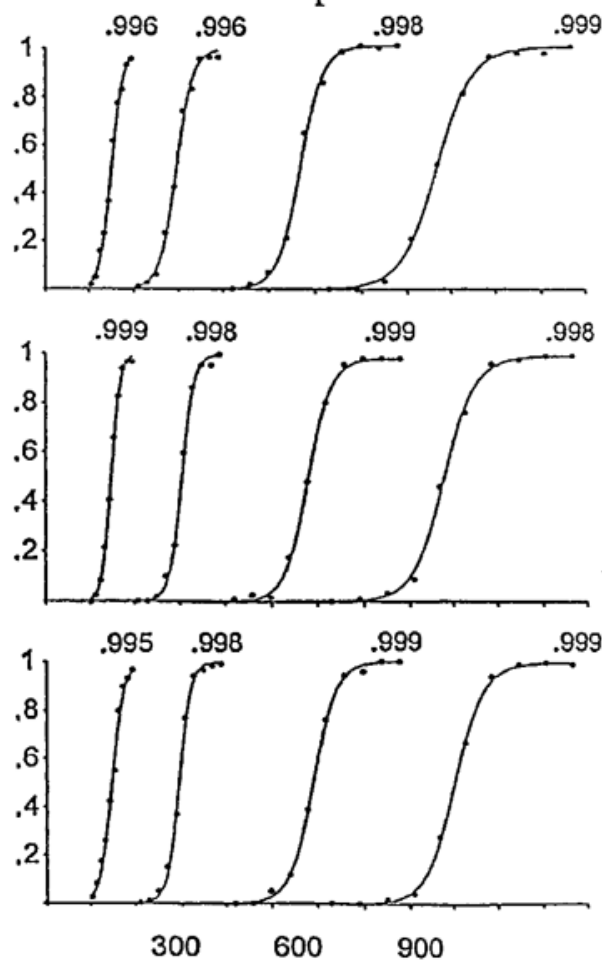

Participant 2

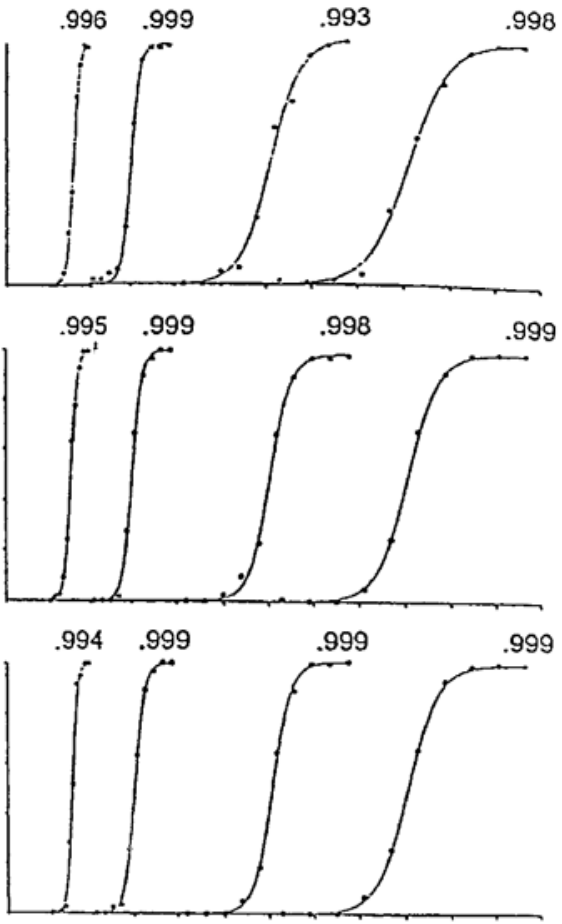

Participant 4

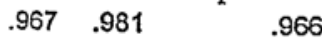

.978

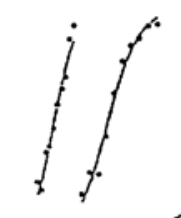

66

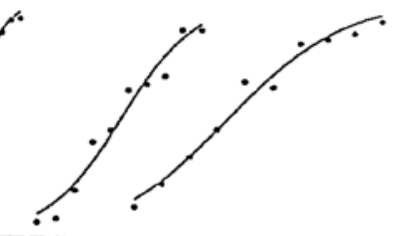

$.943 \quad .985$

.997

.992
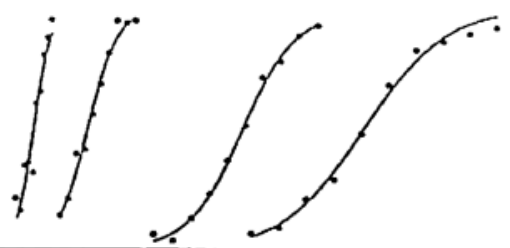

$\begin{array}{lll}964.982 & .993\end{array}$

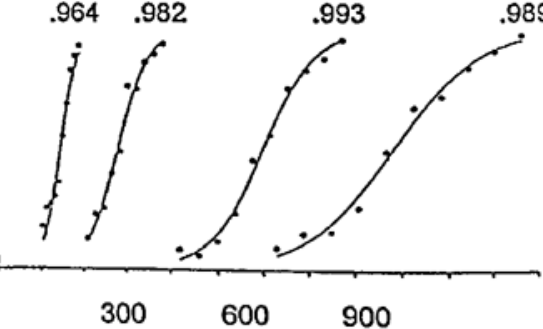

Comparison Interval (msec)

Figure 6. Individual psychometric functions in each experimental condition of Experiment 1B. For each participant, the one-, two-, and three-standards presentation conditions correspond to the upper, middle, and lower panels, respectively. Co, comparison interval; St, standard interval. Numbers above each function are $R^{2}$. 


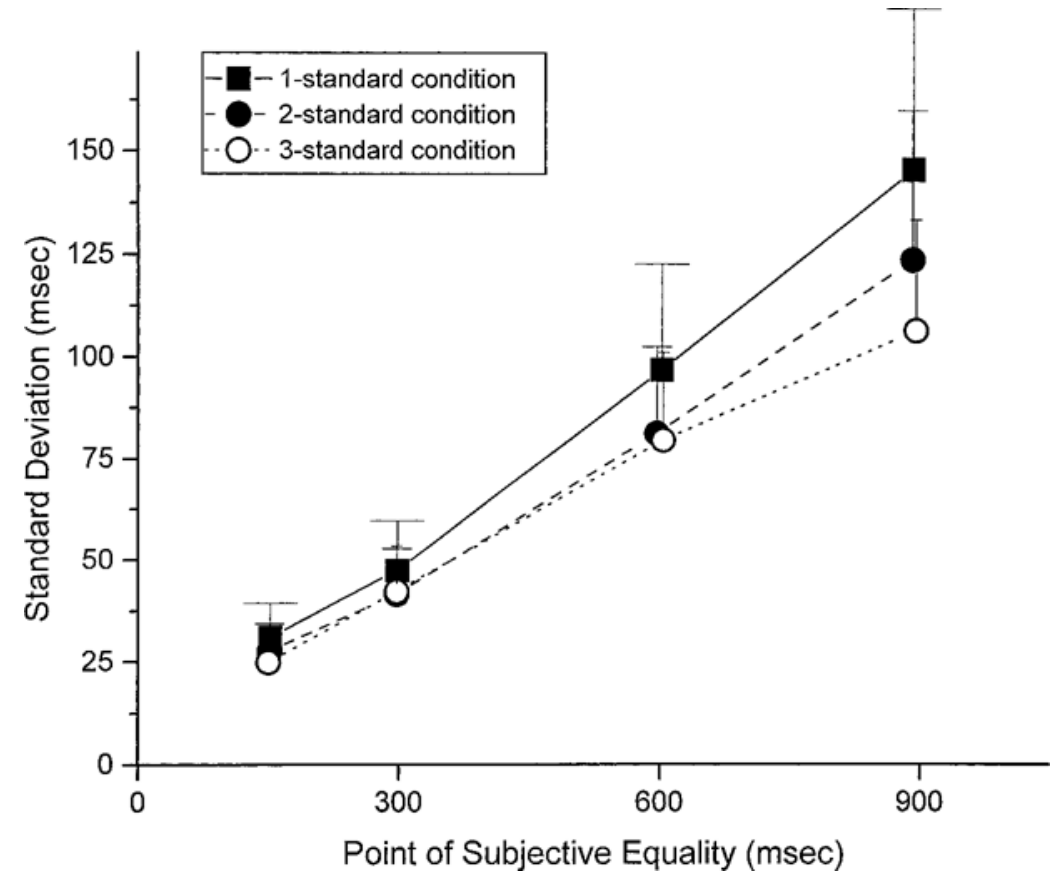

Figure 7. Mean standard deviation, in each experimental condition of Experiment 1B, as a function of the point of subjective equality.

large here as in Experiment $1 \mathrm{~A}$. However, once again, this fraction remained relatively constant over the three longer standard values.

The difference between the means was tested with a randomized block factorial ANOVA $(3$ standards $\times 4$ durations). There were significant effects of duration $[F(3,33)=6.81, p<.01]$ and of number of standards
$[F(2,33)=5.71, p<.01]$. The standard $\times$ duration interaction was not significant $(p=.43)$. Tukey tests on each main effect were not significant.

In order to test whether the method of presentation, continuous versus discontinuous, affects performance, comparisons of WFs in Experiments 1A versus 1B were made. At $150 \mathrm{msec}$, performance was better in the dis-

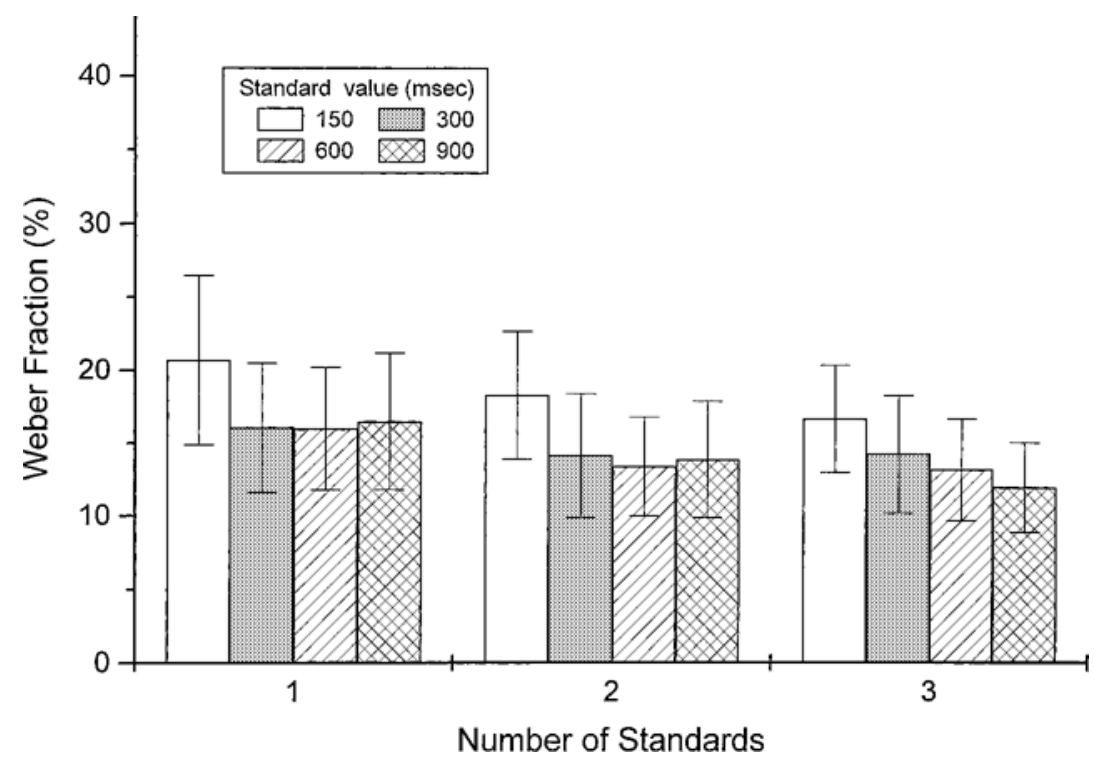

Figure 8. Mean Weber fractions (standard deviation/point of subjective equality) in each experimental condition of Experiment $1 B$. 
continuous condition, but the reverse was observed at 600 and $900 \mathrm{msec}$. For each duration, a 2 (method) $\times 3$ (number of standards) randomized blocked factorial ANOVA was conducted. The effect of method was significant at $150 \mathrm{msec}[F(1,15)=9.28, p<.01]$, at $600 \mathrm{msec}$ $[F(1,15)=8.29, p<.05]$, and at $900 \mathrm{msec}[F(1,15)=5.25$, $p<.05]$, but not at $300 \mathrm{msec}[F(1,15)=0.62, p=.45]$.

Constant error. Mean CEs in each experimental condition are reported in Figure 9. Overall, as in Experiment $1 \mathrm{~A}$, there was no tendency for the comparison interval(s) to be perceived as shorter than the previous one(s). CEs were generally smaller than those in Experiment 1A. At $900 \mathrm{msec}$, the CEs were the largest and were, as in Experiment $1 \mathrm{~A}$, negative.

The difference between the means was tested with a randomized block factorial ANOVA (3 standards $\times 4$ durations). No effect was significant.

\section{Discussion of Experiments 1A and 1B}

There were two dependent variables of interest in Experiments $1 \mathrm{~A}$ and $1 \mathrm{~B}, \sigma$ (sensitivity) and $\mathrm{CE}$ (perceived duration). In both the continuous and the discontinuous conditions, the WF was at its minimum in the threestandards condition. This indicates that using more presentations of standards improves temporal perception. However, using more presentations of standards comes at a cost, as was revealed by the $C$ parameter of Equation 2 , which was at its highest in the three-standards condition in both the continuous and the discontinuous conditions. This parameter is associated with the nontemporal noise involved in the temporal discrimination process. The presentation of a visual stimulus is reported to leave a sensory trace, whose duration estimates vary with the various methods employed (Di Lollo \& Bischof, 1995; Loftus \& Irwin, 1998). This sensory noise is particularly high in the three-standards presentation condition, which might be caused by the increased processing load generated by multiple presentations of a visual signal and by the lack of time available for performing this processing. A parallel can be drawn between this explanation and the processing-time hypothesis of Nakajima (1987), which states that the duration of an empty interval is not limited to its physical duration but also incorporates a constant period, $80 \mathrm{msec}$, after this physical duration, necessary to the processing of duration: The greater the amount of time required to process nontemporal information, the less time left to process duration. Also, the fact that the $C$ values are much lower in the discontinuous condition than in the continuous condition would be made possible by the extra time (1.5-sec ISI) available in the discontinuous condition for processing the standard intervals presented.

Two other findings related to sensitivity are worth noting. On the one hand, the data of Experiments $1 \mathrm{~A}$ and 1B show no sign of optimal timing at $600 \mathrm{msec}$ - that is, no lower WFs at $600 \mathrm{msec}$ than at $900 \mathrm{msec}$. This issue was addressed again in Experiment 2. On the other hand, having lower WF values in the continuous condition than in the discontinuous condition indicates that the temporal processing benefits from the continuity of the sequence between the standard and the comparison intervals. This is consistent with a beat-based hypothesis reported by Keele, Nicoletti, Ivry, and Pokorny (1989; see also Ivry \& Hazeltine, 1995) for temporal discrimination. This hypothesis states that judgments of sequences of intervals are made on the basis of the beat induced by the sequence of signals, rather than on the basis of representation of intervals.

As regards CE, the results might have taken two opposite directions. On the one hand, following ten Hoopen et al. (1995), one might have expected more short responses

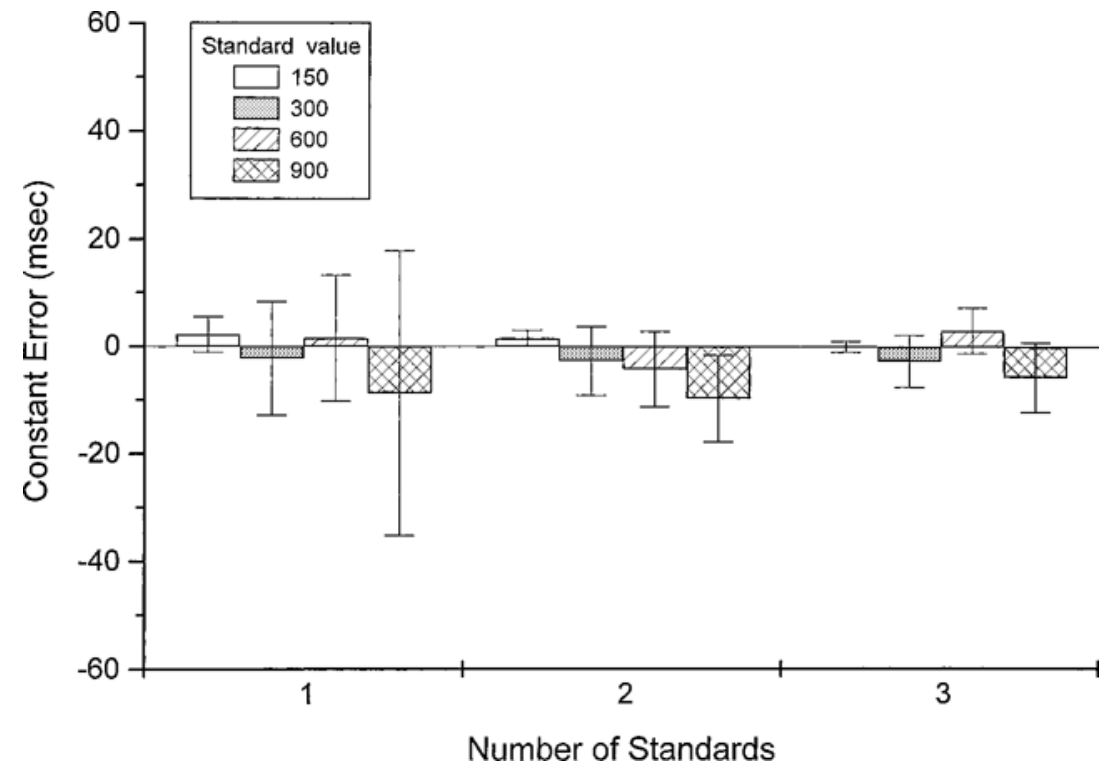

Figure 9. Mean constant errors in each experimental condition of Experiment 1B. 
for the comparison intervals, which were always presented after the standard(s). On the other hand, strictly speaking - that is, if Weber's law holds-a psychometric function should be positively skewed (Killeen et al., 1997). This predicts that the PSE should fall below the point of objective equality (the value that bisects the physical values used for the function) - that is, more long responses should occur. In Experiment 1B, there was no effect (Figure 9). In Experiment 1A, all CEs were negative at 600 and $900 \mathrm{msec}$, and positive at 150 and $300 \mathrm{msec}$ (Figure 5). This indicates that, if there is any tendency to respond short more often, it is with very short intervals, whereas the reverse would be observed with longer intervals. This is compatible with what is usually observed for the TOE for time (Allan \& Gibbon, 1994).

The fact that negative CEs were observed at 600 and $900 \mathrm{msec}$, but not with shorter intervals, can be explained by the relative contribution, in the discrimination process, of temporal and nontemporal sources of variance at various duration ranges. With very short intervals, the contribution of nontemporal factors is very important. With longer intervals (600 and $900 \mathrm{msec}$ ), timing is purer-that is, the variance observed is dominated by the temporal source. This makes for psychometric functions closer to those predicted (1) by Killeen et al. (1997) (i.e., functions positively skewed) or (2) by the scalar theory of timing when a bisection task is employed (i.e., functions with the PSE falling at the geometric mean, but not at the arithmetic mean, of the referent intervals; Allan \& Gibbon, 1991).

\section{EXPERIMENT 2}

Experiment 2 was a replication of Experiment 1 with a larger sample. Only 600- and 900-msec durations (the region of possible optimal timing) were used, and the continuous/discontinuous distinction was drawn between, rather than within, observers.

\section{Method}

Participants. Sixteen volunteer students from Université Laval, 11 females and 5 males, 21 to 36 years of age, participated in this experiment. The 8 participants who participated in the Continuous condition of the experiment received $\$ 24$, and the 8 participants who participated in the slightly longer discontinuous condition received $\$ 28$.

Apparatus and Stimuli. The material was the same as that in Experiments $1 \mathrm{~A}$ and $1 \mathrm{~B}$.

Procedure. There were two standard intervals, 600 and 900 msec, under investigation in Experiment 2. The same comparison intervals as those for the previous experiments were employed, which made it possible to construct psychometric functions. The one- and three-standards presentation conditions were retained for the present experiment. Both modes of presentation, continuous (exactly as in Experiment 1A) and discontinuous (exactly as in Experiment $1 \mathrm{~B}$ ), were employed and were separate parts of the experiment. The method (presentation of signals, number of trials and blocks) within each session was the same as that in the previous experiment. Eight of the participants participated in the continuous part of the experiment, and the other 8 participants participated in the discontinuous part. All participated in four sessions, one for each of the four experimental conditions: 2 (standard duration) $\times$ 2 (number of standards). The order of presentation of these four sessions was balanced according to a Latin square.

\section{Results}

As in Experiment 1, an individual psychometric function was traced for each experimental condition, and Equation 1 was used to fit the data points. As is illustrated in Figure 10, there was not much difference between the WFs at 600 and $900 \mathrm{msec}$. However, these fractions were lower in the three- than in the one-standard presentation condition, at least for the discontinuous condition.

The difference between the mean WFs for each condition was tested with a repeated measures factorial ANOVA: 2 durations $(600$ or $900 \mathrm{msec}) \times 2$ standards $(1$ or 3$) \times 2$ modes of presentation (continuous or discontinuous). The results showed a significant difference only for the number-of-standards effect $[F(1,14)=5.11$, $p<.05]$.
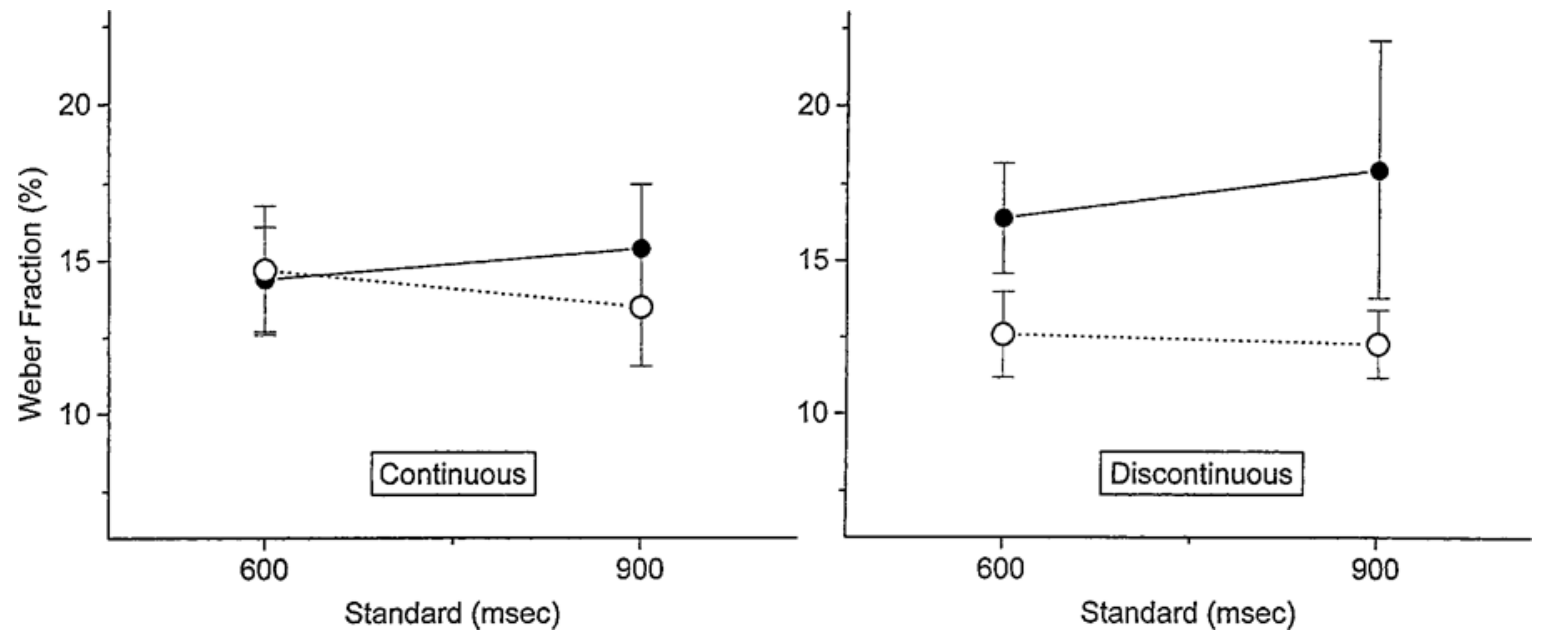

Figure 10. Mean Weber fractions (standard deviation/point of subjective equality) in each experimental condition of Experiment 2 . 
Figure 11 shows that CEs were generally negative and that the CE values were, in all the experimental conditions ( 2 standards $\times 2$ modes), lower at $900 \mathrm{msec}$ than at $600 \mathrm{msec}$. The difference between the mean CEs was also tested with an ANOVA, following the same design as that described earlier, and only the effect of duration was significant $[F(1,14)=6.29, p<.05]$.

\section{Discussion}

Experiment 2 revealed that, at 600 and $900 \mathrm{msec}$, there was no sensitivity difference between the continuous and discontinuous modes of interval presentation, with the WF at about $15 \%$. This is not consistent with Experiment 1 , where, for these durations, better discrimination was obtained with the continuous (WF $\cong 10 \%$ ) than with the discontinuous (WF $\cong 13 \%$ ) mode. The following experiment provided a new test regarding this issue.

Sensitivity was significantly affected by the number of standards presented. The more standards that were presented, the greater was sensitivity. Nevertheless, as a careful inspection of Figure 10 suggests, this number-ofstandards effect seemed to apply only to the discontinuous condition. Along the same line, the data from Experiment 1 also suggested, especially at $900 \mathrm{msec}$, better discrimination with more presentations of standards. Experiment 3 provided new comparisons for this numberof-standards and mode issue.

The WFs analysis clearly revealed no difference between the 600- and the 900-msec conditions. This is consistent with Experiment 1 and suggests that there is no optimal timing for the $600-\mathrm{msec}$ value. However, it does not exclude the possibility that an optimal timing may occur at some point between these values (Mishima, 1956, in Fraisse, 1981). ${ }^{3}$

Finally, the duration effect for the CE indicated that the participants perceived comparison intervals as being longer than the standard more often at $900 \mathrm{msec}$ than at
$600 \mathrm{msec}$. Whereas CEs were close to 0 at $600 \mathrm{msec}$, they were about $-22 \mathrm{msec}$ at $900 \mathrm{msec}$. Indeed, at $600 \mathrm{msec}$, the CEs were negative in the continuous condition, as in Experiment 1A, and positive in the discontinuous condition, as in Experiment 1B (one- and three-standards presentation conditions). The negative values at $900 \mathrm{msec}$ indicated that intervals presented in the second part (comparison intervals) were perceived as longer, a result that is consistent with the negative values of Experiments 1A and $1 \mathrm{~B}$ and with the TOE, where the last intervals presented are perceived as being longer (Allan \& Gibbon, 1994).

\section{EXPERIMENT 3}

In the first two experiments, there was no obvious trace of a preferred duration (lower WF) at $600 \mathrm{msec}$. The sensory differences between auditory and visual signals may explain why there was no optimal timing at 600 msec in the present experiments, as has sometimes been reported with auditory sequences. There might simply be no such optimal timing for vision. However, it is possible that the value for optimal timing was simply shifted to a longer value.

Experiment 3 was designed to search for this optimal value for a range that was not under investigation in the previous experiments. Two standard durations, 900 and $1,200 \mathrm{msec}$, were employed. We also opted to use twoand four-standards presentations, instead of one and three. The one- versus three-standards difference was reported to affect sensitivity, although the results were more obvious in the discontinuous condition than in the continuous condition. Experiment 3 provided a test to see whether more (four) standard presentations would continue to improve sensitivity. Moreover, this allowed, for the 900-msec condition, direct comparisons of the one- with the four-standards presentation conditions to be made.
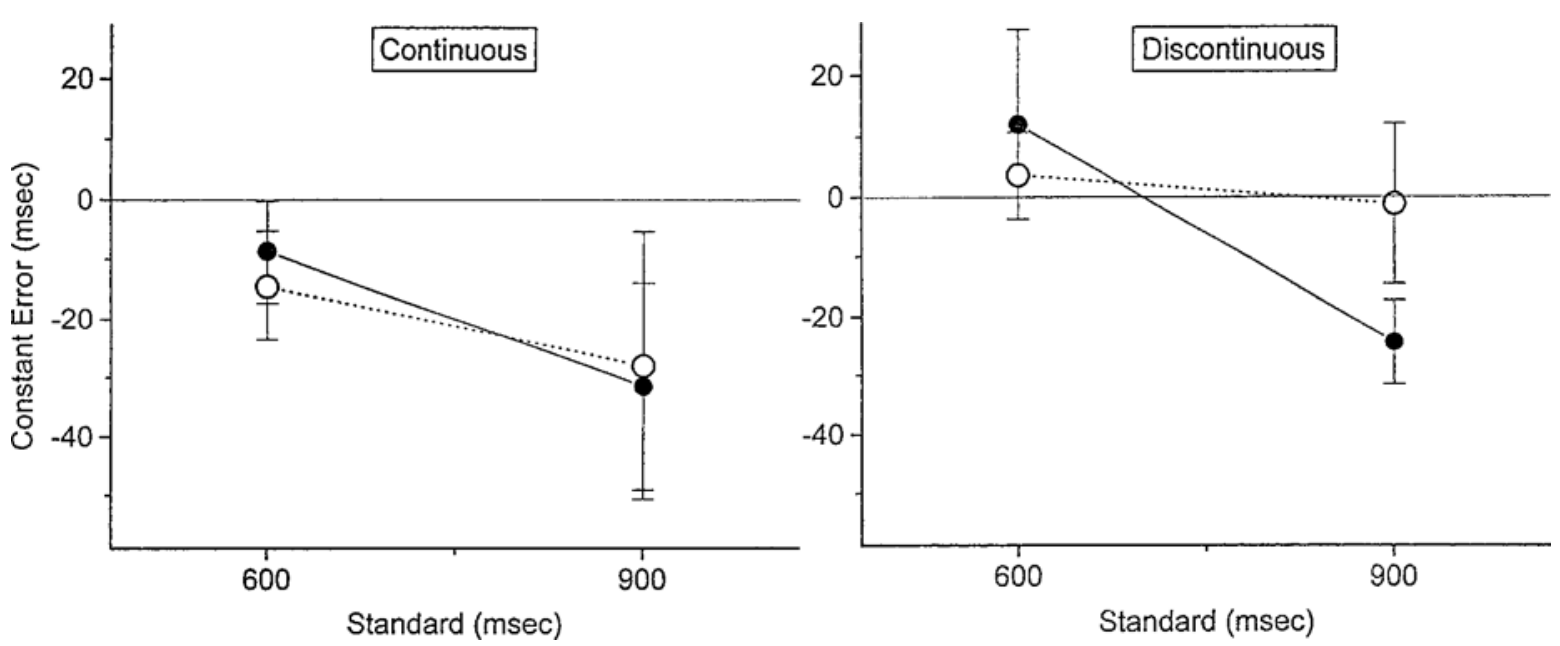

Figure 11. Mean constant errors in each experimental condition of Experiment 2. 


\section{Method}

Participants. Sixteen adult volunteer participants from Université Laval, 8 males and 8 females, participated in the experiment. They were paid $\$ 28$ (continuous condition) or $\$ 32$ (discontinuous condition).

Apparatus and Stimuli. The material was the same as that in Experiments 1A, 1B, and 2.

Procedure. The procedure was exactly the same as that in Experiment 2, except for three features. First, two and four standardinterval presentations, instead of one and three, were used. Second, standard values of 900 and $1,200 \mathrm{msec}$, instead of 600 and $900 \mathrm{msec}$, were under investigation. For this $1,200-\mathrm{msec}$ condition, the 10 short-to-long comparison intervals lasted from 860 to $1,560 \mathrm{msec}$. Finally, for this 1,200-msec condition, a 2-sec ISI (instead of 1.5 $\mathrm{sec}$ ) was employed to ensure that the ISIs and the comparison intervals would appear clearly different, as they do when the standard intervals equal $900 \mathrm{msec}$.

\section{Results}

As in the previous experiments, one individual psychometric function was traced for each experimental condition, and Equation 1 was used to fit the data points. Figure 12 shows that, for all four conditions, the WFs were higher at $1,200 \mathrm{msec}$ than at $900 \mathrm{msec}$.

The difference between the mean WFs for each condition was tested with a repeated measures factorial ANOVA: 2 durations $(900$ or $1,200 \mathrm{msec}) \times 2$ standards $(2$ or 4$) \times 2$ modes of presentation (continuous or discontinuous). Only the effect of duration was significant $[F(1,14)=6.44, p<.05]$.

Figure 13 shows that CEs were all negative in the discontinuous condition but were all positive in the continuous condition. In the discontinuous continuous, the magnitudes of the negative CEs were about the same for the two- and four-standards presentation conditions. In the continuous condition, CEs were larger in the twostandards presentation condition, but individual differences were very large. An ANOVA on CEs, following the same design as that described earlier, revealed no significant main effect, but the mode-of-presentation effect was marginally significant $[F(1,14)=4.48, p=.053]$. No double interaction was significant, but the triple interaction was $[F(1,14)=6.25, p<.05]$.

\section{Discussion}

The main finding of Experiment 3 was the significant duration effect for the WF. For each of four experimental conditions (two- or four-standards presentations in the continuous or the discontinuous condition), the WF was higher at $1,200 \mathrm{msec}$ than at $900 \mathrm{msec}$. This is a clear case of violation of Weber's law, even in its generalized form. This finding suggests that there is a range for which discrimination is optimal and that this range ends below 1,200 msec.

\section{GENERAL DISCUSSION}

There were essentially two dependent variables of interest in the present series of experiments, one related to sensitivity and another related to the perceived duration of the comparison intervals. Because it is difficult to derive clear meaning from this latter variable, the discussion below is centered on sensitivity. The analysis of sensitivity for various base durations was made by using two experimental manipulations: the number of standard intervals presented and continuity or discontinuity between the standard and the comparison intervals.

\section{Weber Issues}

One critical question addressed in this article is whether or not the difference threshold would remain a constant value over a given range of short durations, as is sometimes reported for brief auditory patterns (Schulze, 1989; ten Hoopen et al., 1995). With visual sequences, the results are somewhat consistent with this auditory finding, since the thresholds, in the continuous condition (Experiment 1A), were higher at $150 \mathrm{msec}$ than at 300 msec. Moreover, the use of more presentations of stan-
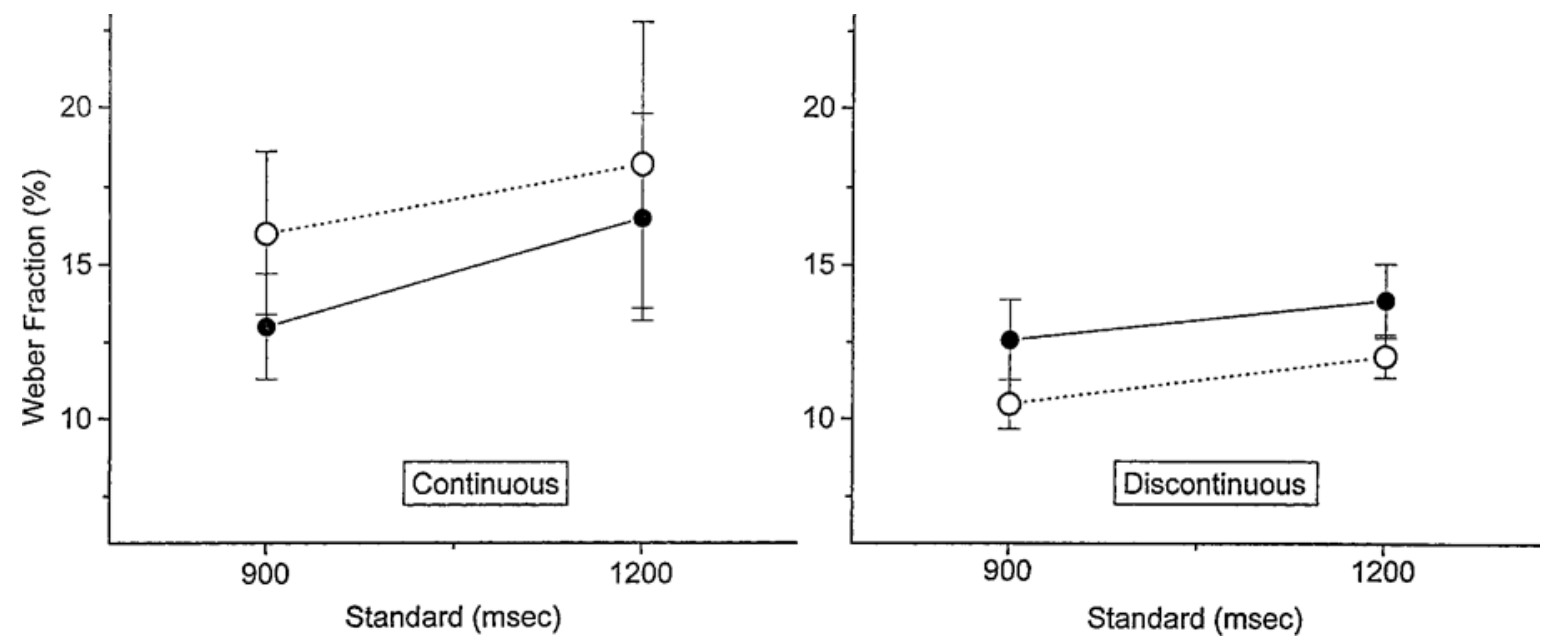

Figure 12. Mean Weber fractions (standard deviation/ point of subjective equality) in each experimental condition of Experiment 3. 

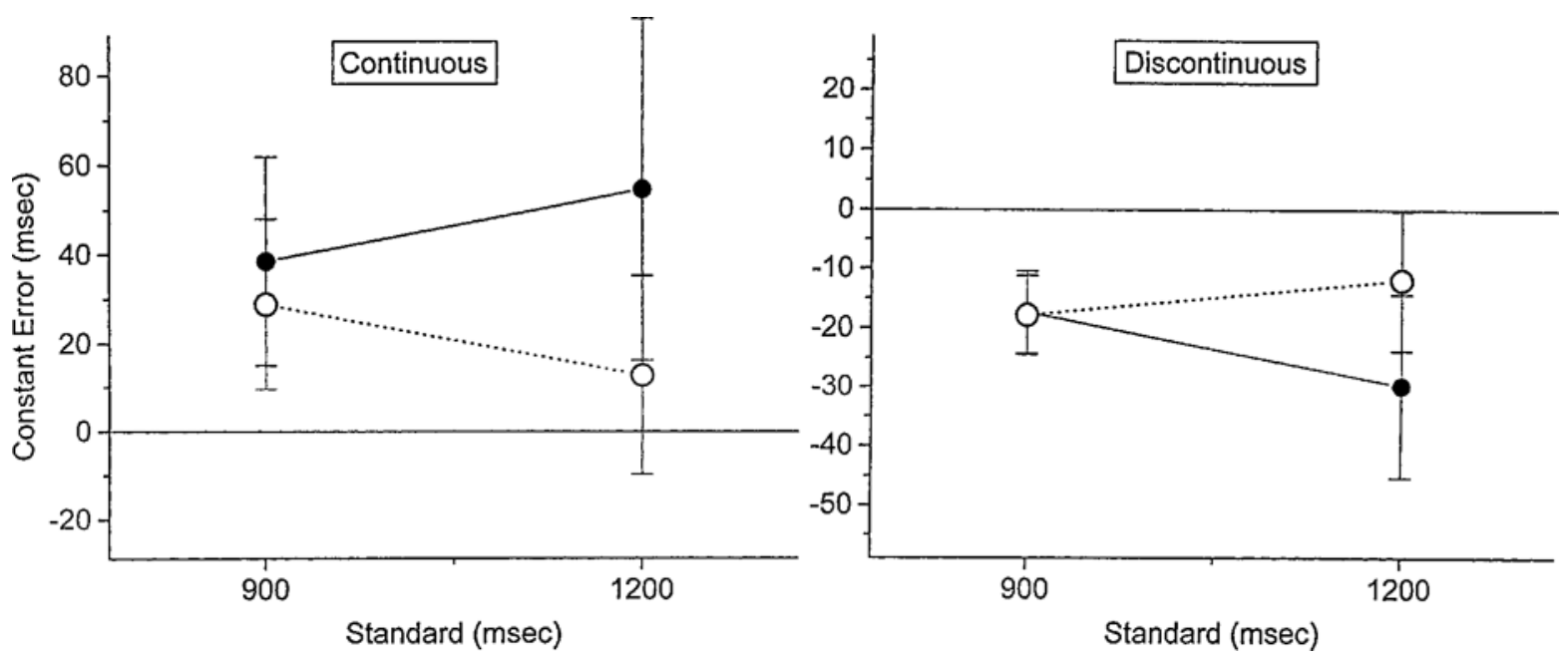

Figure 13. Mean constant errors in each experimental condition of Experiment 3.

dards provoked more problems, given that the threshold remained almost constant, in the three-standards condition, from 150 to $600 \mathrm{msec}$. In other words, adding more intervals also meant adding more sensory noise, as is indicated by the intercept values ( $C$ in Equation 2$)$ in Tables 1 and 2 . This noise probably does not simply have an additive effect on the variance observed in the duration discrimination process. From a perspective in which the total variance observed in duration discrimination is due to the addition of the variance of a duration-dependent component and of a duration-independent component (Getty, 1975; Ivry \& Hazeltine, 1995), to have at least as much variance at $150 \mathrm{msec}$ as at $300 \mathrm{msec}$ does not make sense. Not only does the succession of sensory signals add variance, but it may even interfere with the durationdependent component of the timing process. If this duration-dependent component consists of a pacemakercounter device, one may tentatively suppose that the rapid succession of sensory events exerts an influence, perhaps as a result of higher arousal, on the rate of pulse emission of the pacemaker (Penton-Voak, Edwards, Percival, \& Wearden, 1996). On the other hand, a simpler interpretation is that efficiency in processing the sensory signals themselves is time related, with not having enough time decreasing efficiency, as would be the case at 150 msec. In other words, the nontemporal component does not have a constant variance value; it would be duration independent, in the sense that sensory processing does not depend on the activity of the internal clock device, but it would not be independent of physical time, since real time is needed for sensory processing.

A very important finding in the present article is the larger WFs observed in the 1,200-msec condition than in the 900-msec condition (Experiment 3). This duration effect did not interact with the number of standards presented or with the presentation mode. In other words, for interval discrimination marked by sequences of visual signals, the generalized form of Weber's law is confined to a description limited, in its longest possible limit, to $1,200 \mathrm{msec}$. When one considers that, with very short intervals in the continuous condition, the Weber function also encounters problems, a researcher is left with a tool, the Weber function, that may be applied only to a very narrow band (Grondin, 2001). Problems with the application of this function to duration discrimination have also been observed in connection with very intense training procedures, which led to a step function (Kristofferson, 1980), and when an explicit-counting strategy was used, which led to a constant difference threshold (Grondin, Meilleur-Wells, \& Lachance 1999). Dissatisfaction over Weber's law has also been voiced in the animal timing literature (Staddon \& Higa, 1999). Perhaps Weber's law does not have to hold if timing errors depend on memory processes (Staddon \& Higa, 1996, 1999) or if the main source of variance of a pacemaker-counter device is located within the various stages of a fallible counter (Killeen \& Taylor, 2000).

\section{Method Issues}

From a strict empirical viewpoint, we can affirm that increasing the number of standard presentations was, if anything, more advantageous in the discontinuous condition than in the continuous condition. Figure 14, which combines the results of Experiments 2 and 3, at 900 $\mathrm{msec}$, indicates that more presentations of standards improves performance in the discontinuous condition, but not in the continuous condition. The overall picture is quite clear in the discontinuous condition (Experiments $1 \mathrm{~A}, 2$, and 3 ), in which using more intervals provides better discrimination. In the continuous condition, the number-of-standards effect depends on the duration of the standard. As was revealed by the two- versus fourstandards presentations in Experiment 3, as well as by the comparison of the one- to three-standards presenta- 


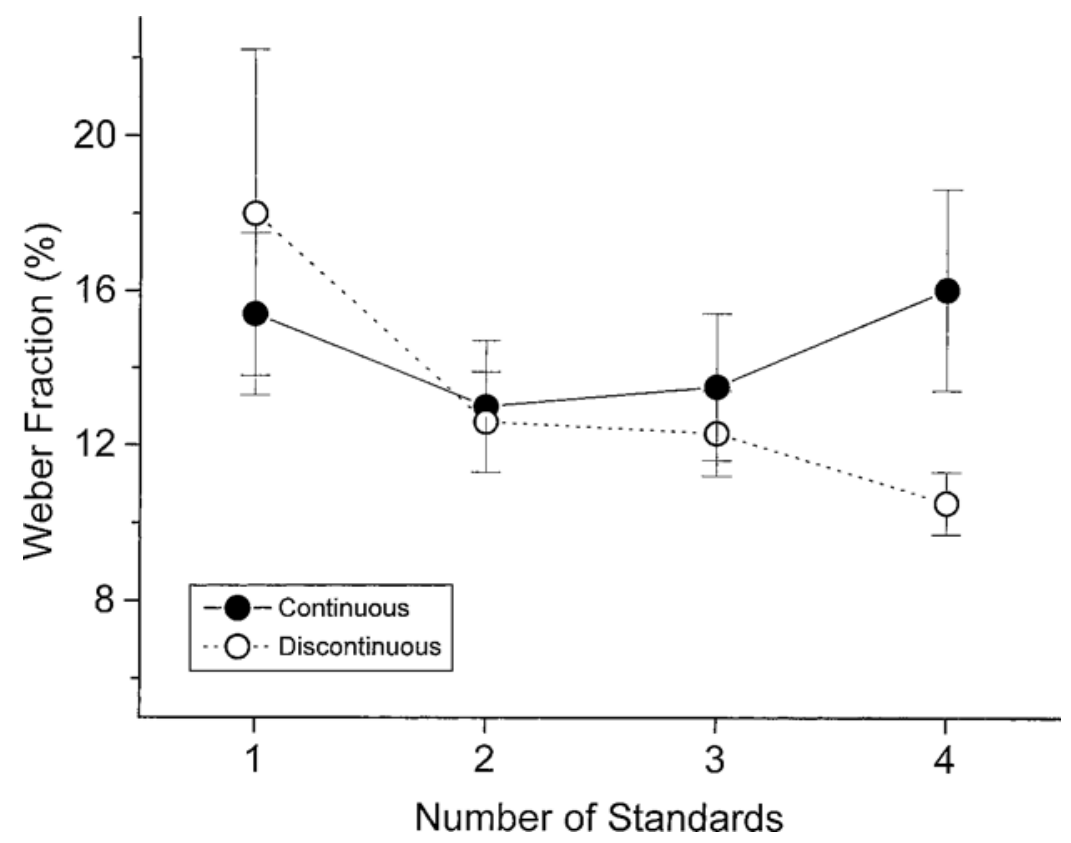

Figure 14. Mean Weber fractions, for a 900 -msec standard, in the continuous and discontinuous conditions (from Experiments 2 and 3 ).

tions at $150 \mathrm{msec}$ in Experiment 1A, the use of more presentation s of standards tends to deteriorate performance.

The results for the discontinuous method are consistent with previous findings for which a method close to that the for discontinuous condition (with an ISI) of the present experiment was used (Drake \& Botte, 1993; McAuley \& Kidd, 1998). Drake and Botte explained their results by the fact that having more intervals in the first sequence allows development of a more precise memory trace of mean interval duration.

Finally, in Experiment 1, the WFs stemming from Equation 2 were lower in the continuous condition than in the discontinuous condition. This has prompted suggestions that the continuous condition may benefit from a beatbased mode for processing time (Keele et al., 1989), an advantage not available in the discontinuous the condition because of the discontinuity of the sequence between the standard and the comparison intervals presented. However, this beat-based advantage is challenged by Experiments 2 and 3 , in which results were not better in the continuous condition. Indeed, when more standard intervals (three in Experiment 2, four in Experiment 3) were presented, performance tended to be better in the discontinuous condition.

\section{Conclusion}

The purpose of the present study was to extend to the visual mode findings observed in the auditory rhythm literature, which indicate violations of the generalized form of Weber's law for the discrimination of time intervals marked by sequences of brief tones. The results of the present series of experiments do extend previous au- ditory findings to the visual mode-namely, (1) within a range of short durations and when using a continuous mode of presentation of intervals, the nontemporal variance in the discrimination process is such that the difference threshold, more than the WF, remains constant over time, and (2) the range of durations for which the WF remains constant is narrow, given that the fraction is higher at 1,200 msec than at $900 \mathrm{msec}$.

\section{REFERENCES}

Allan, L. G. (1998). The influence of the scalar timing model on human timing research. Behavioral Processes, 44, 101-117.

Allan, L. G., \& GibBon, J. (1991). Human bisection at the geometric mean. Learning \& Motivation, 22, 39-58.

Allan, L. G., \& GibBon, J. (1994). A new temporal illusion or the TOE once again? Perception \& Psychophysics, 55, 227-229.

Allan, L. G., \& Kristofferson, A. B. (1974). Psychophysical theories of duration discrimination. Perception \& Psychophysics, 16, 26-34.

Di Lollo, V., \& Bischof, W. F. (1995). Inverse-intensity effect in duration of visible persistence. Psychological Bulletin, 118, 223-237.

Drake, C., \& Botte, M.-C. (1993). Tempo sensitivity in auditory sequences: Evidence for a multiple-look model. Perception \& Psychophysics, 54, 277-286.

FrAISSE, P. (1967). Le seuil différentiel de durée dans une suite régulière d'intervalles [Different threshold for duraton in a regular series of intervals]. L'Année Psychologique, 67, 43-49.

Fraisse, P. (1981). Multisensory aspects of rhythm. In R. D. Walk \& H. L. Pick (Eds.), Intersensory perception and sensory integration (pp. 217-248). New York: Plenum.

Friberg, A., \& Sundberg, J. (1995). Time discrimination in a monotonic, isochronic sequence. Journal of the Acoustical Society of America, 98, 2524-2531.

GetTy, D. J. (1975). Discrimination of short temporal intervals: A comparison of two models. Perception \& Psychophysics, 18, 1-8.

GRONDIN, S. (1993). Duration discrimination of empty and filled intervals marked by auditory and visual signals. Perception \& Psychophysics, 54, 383-394. 
Grondin, S. (2001). From physical time to the first and second moments of psychological time. Psychological Bulletin, 127, 22-44.

Grondin, S., Meilleur-Wells, G., \& Lachance, R. (1999). When to start explicit counting in a time-intervals discrimination task: A critical point in the timing process of humans. Journal of Experimental Psychology: Human Perception \& Performance, 25, 993-1004.

Grondin, S., Ouellet, B., \& Roussel, M.-E. (2001). About optimal timing and stability of Weber fraction for duration discrimination. Acoustical Science \& Technology, 22, 370-372.

HAlpern, A. R. \& Darwin, C. J. (1982). Duration discrimination in a series of rhythmic events. Perception \& Psychophysics, 31, 86-89.

HELlST RÖM, $\AA$. (1985). The time-order error and its relatives: Mirrors of cognitive processes in comparing. Psychological Bulletin, 97, 35-61.

Hirsh, I. J., Monahan, C. B., Grant, K. W., \& Singh, P. G. (1990). Studies in auditory timing: 1 . Simple patterns. Perception \& Psychophysics, 47, 215-226.

IVRY, R. B., \& HAZELTine, R. E. (1995). The perception and production of temporal intervals across a range of durations: Evidence for a common timing mechanism. Journal of Experimental Psychology: Human Perception \& Performance, 21, 3-18.

Jamieson, D. G., \& Petrusic, W. M. (1975a). Pairing effects and timeorder errors in duration discrimination. Perception \& Psychophysics, 18, 107-113.

Jamieson, D. G., \& Petrusic, W. M. (1975b). Presentation order effects in duration discrimination. Perception \& Psychophysics, 17, 197-202.

Keele, S. W., Nicoletti, R., Ivry, R., \& Pokorny, R. A. (1989). Mechanisms of perceptual timing: Beat-based or interval-based judgements? Psychological Research, 50, 251-256.

Killeen, P. R. Fetterman, J. G., \& Bizo, L. A. (1997). Time's causes. In C. M. Bradshaw \& E. Szabadi (Eds.), Time and behavior: Psychological and neurobehavioral analyses (pp. 79-131). Amsterdam: Elsevier.

Killeen, P. R. \& TAYloR, T. (2000). How the propagation of error through stochastic counters affects time discrimination and other psychophysical judgments. Psychological Review, 107, 430-459.

Killeen, P. R, \& Weiss, N. A. (1987). Optimal timing and the Weber function. Psychological Review, 94, 455-468.

KIRK, R. E. (1982). Experimental design: Procedures for the behavioral science. Belmont, CA: Brooks/Cole.

Kristofferson, A. B. (1980). A quantal step function in duration discrimination. Perception \& Psychophysics, 27, 300-306.

LofTUS, G. R. \& IRWIN, D. E. (1998). On the relations among different measures of visible and informational persistence. Cognitive Psychology, 35, 135-199.

McAuley, J. D., \& KidD, G. R. (1998). Effect of deviations from temporal expectations on tempo discrimination of isochronous tone sequences. Journal of Experimental Psychology: Human Perception \& Performance, 24, 1786-1800.

Mishima, J. (1956). On the factors of the mental tempo. Japanese Psychological Research, 4, 27-38.

Monahan, C. B., \& Hirsh, I. J. (1990). Studies in auditory timing: 2. Rhythm patterns. Perception \& Psychophysics, 47, 227-242.

Nakajima, Y. (1987). A model of empty duration perception. Perception, 16, 485-520.

Nakajima, Y., ten Hoopen, G., Hilkhuysen, G., \& Sasaki, T. (1992). Time-shrinking: A discontinuity in the perception of auditory temporal patterns. Perception \& Psychophysics, 51, 504-507.

NAKAJima, Y., TEN Hoopen, G., \& VAN DER Wilk, R. G. H. (1991). A new illusion of time perception. Music Perception, 8, 431-448.
Penton-Voak, I. S., Edwards, H., Percival, A., \& Wearden, J. H. (1996). Speeding up an internal clock in humans: Effects of click trains on subjective duration. Journal of Experimental Psychology: Animal Behavior Processes, 22, 307-320.

Rose, D., \& Summers, J. (1995). Duration illusions in a train of visual stimuli. Perception, 24, 1177-1187.

Schulze, H. H. (1989). The perception of temporal deviations in isochronic patterns. Perception \& Psychophysics, 45, 291-296.

Staddon, J. E. R., \& Higa, J. J. (1996). Multiple time scales in simple habituation. Psychological Review, 103, 720-733.

Staddon, J. E. R., \& Higa, J. J. (1999). Time and memory: Towards a pacemaker-free theory of interval timing. Journal of the Experimental Analysis of Behavior, 71, 215-251.

ten Hoopen, G., Boelaarts, L., Gruisen, A., Apon, I., Donders, K., Mul, N., \& AKerboom, S. (1994). The detection of anisochrony in monaural and interaural sound sequences. Perception \& Psychophysics, 56, 110-120.

ten Hoopen, G., Hartsuiker, R, Sasaki, T., Nakajima, Y., Tanaka, M., \& Tsumura, T. (1995). Auditory isochrony: Time shrinking and temporal patterns. Perception, 24, 577-593.

ten Hoopen, G., Hilkhuysen, G., Vis., G., NaKajima, Y., Yamauchi, F., \& SASAKI, T. (1993). A new illusion of time perception: II. Music Perception, 11, 15-38.

\section{NOTES}

1. In a pilot study, 50- and 100-msec standard intervals were employed. However, in many cases, the participants were simply unable to perform the task. Some participants simply made time judgments on the basis of the entire sequence (standard[s] + comparison) by comparing its length with the entire sequences of previous trials.

2. It is noteworthy that psychometric functions in Experiment $1 \mathrm{~A}$ and $1 \mathrm{~B}$ were also fitted with the CND. If there is no increase of the difference thresholds with longer durations-as in ten Hoopen et al. (1995), for instance-then a better fit for the data points on the psychometric functions should be provided by the CND model than by Equation 1. On the other hand, if Weber's law applies, a better fit should be expected from Equation 1 than from the standard Gaussian model. Although the fits were generally very good with the CND too, for 35 out of 48 psychometric functions in Experiment 1A, the goodness of fit was higher when using Equation 1. In Experiment 1B, for 32 out of 48 psychometric functions, the goodness of fit was higher when using Equation 1, rather than the CND. Thus, for both Experiments 1A and 1B, 67 out of the 96 psychometric functions were better fitted with Equation 1 than with the CND. This frequency difference is significant $\left(\chi^{2}=15.04, p<.01\right)$.

3 . The possibility that optimal timing (lower WF) might occur at some point in the vicinity of $600 \mathrm{msec}$ was tested in an experiment in which difference thresholds were compared for several standard durations $(500,560,620,680$, and $740 \mathrm{msec})$. Difference thresholds were estimated on the basis of an adaptive procedure in which only one standard and one comparison interval, separated by a 1.5 -sec interval, were presented to participants $(n=16)$ during each trial. There were no significant differences in the WFs between the standard duration conditions, whether the intervals to be discriminated were marked either by brief visual signals or by brief auditory signals (Grondin, Ouellet, \& Roussel, 2001). However, discrimination was consistently better with auditory than with visual signals.

(Manuscript received July 12, 1999 revision accepted for publication January 25, 2001.) 